\title{
Comparative Study of the Acute Toxicity of Fluoxetine Versus Amitriptyline and the Predictive Factors for Their Complications
}

\author{
Gihan B. Azab and Eglal H. ELawady ${ }^{1}$ \\ ${ }^{1}$ Departments of Forensic Medicine \&Clinical Toxicology, Faculty of Medicine, Ain Shams University, Cairo, \\ Egypt.
}

\begin{abstract}
The aim of this study is to compare acute toxicity of fluoxetine versus that of amitriptyline among patients admitted to the Poison Control Centre, Ain Shams University (PCC-ASU) and to investigate some predictive factors for the development of complications in such cases. METHODS: A prospective study was conducted in the PCC-ASU during the period between January 2013 and December 2015. The study included 31 patients ingested fluoxetine alone and 49 patients ingested amitriptyline alone. Parameters: Descriptive variables: (age, gender, amount taken, delay time and manner of poisoning). Clinical variables: Vital signs, mean QRS duration, corrected QT (QTc), cardiac arrhythmias ,level of consciousness (assessed by Glasgow coma scale (GCS), pupil size and reactivity, seizures and symptoms of serotonin toxicity. Laboratory variables: (Serum sodium, potassium, calcium and magnesium and blood glucose level).The outcome variables: percentage of cases with: cardiac arrhythmias, QRS $\geq 100$, QTc $\geq 440$, seizures, GCS $\leq 10$, serotonin toxicity, ICU admission, length of stay in ICU, length of hospital stay and survival. RESULTS: there was highly significant increase of the age, amount of drug ingested, mean QRS, QTc, mydriasis and significant decrease in the mean GCS and serum sodium in amitriptyline group compared to fluoxetine group. A highly significant increase of percentage of tremors, clonus, hyper-reflexia and diaphoresis was observed in fluoxetine group. As regards outcome variables, there was insignificant difference in percentage of cases with seizures and survival between both groups. There was significant increase in percentage of cases with QRS $\geq 100$, QTc $\geq 440$, GCS $\leq 10$, ICU admission, length of stay in ICU and hospital in amitriptyline group. There was a highly significant increase of cases with serotonin toxicity in fluoxetine group. The patients who developed seizures after acute amitriptyline toxicity, showed a highly significant increase in the amount of drug intake, QRS, QTc duration and length of hospital stay and highly significant decrease of mean GCS and serum sodium level compared with patients without seizures. By applying logistic regression analysis, QRS $\geq 100$ and $\mathrm{QTc} \geq 440$ interval and $\mathrm{GCS} \leq 10$ were identified as independent risk factors and QRS $\geq 100$ showed (sensitivity $97 \%$, specificity $71 \%$, PPV $67 \%$ and NPV $97 \%$ ); QTc $\geq 440$ interval showed (sensitivity $65 \%$,specificity $64 \%$, PPV55\% and NPV 68\%) and GCS $\leq 10$ showed (sensitivity $86 \%$, specificity $71 \%$, PPV $60 \%$ and NPV $80 \%$ ). The patients who developed seizure after acute fluoxetine toxicity showed a highly significant increase in the amount of drug intake, QTc duration, and percentage of cases with serotonin toxicity and length of hospital stay and highly significant decrease of mean GCS compared with patients without seizures. By applying logistic regression analysis, QTc $\geq 440, \mathrm{GCS} \leq 10$, and serotonin toxicity were identified as independent risk factors. QTc interval $\geq 440$ showed (sensitivity $62 \%$, specificity $82 \%$, PPV $55 \%$ and NPV $86 \%$ ); GCS $\leq 10$ showed (sensitivity $72 \%$, specificity $84 \%$, PPV $60 \%$ and NPV 91\%) and serotonin toxicity showed (sensitivity 100\%, specificity $86 \%$, PPV72\% and NPV 100\%). IN CONCLUSION: Fluoxetine intoxicated patients encountered complications as serotonin toxicity and seizure in acute large doses and the predictive risk factors for seizure were QTc $\geq 440, \mathrm{GCS} \leq 10$ and serotonin toxicity. Amitriptyline intoxication associated with seizures and the predictive risk factors for seizure were QRS $\geq 100$ and $\mathrm{QTc} \geq 440$ and GCS $\leq 10$.
\end{abstract}




\section{Introduction}

Mricyclic antidepressants (TCAs), of which amitriptyline (Tryptizol ${ }^{\circledR}$ ) is a prototype that is used widely to treat many neuro-psychiatric diseases, have remained one of the common causes of fatal drug poisoning and a leading cause of death among intentional overdoses world wild (Bek et al., 2008; Kiberd and Minor, 2012). Amitriptyline poisoning is often lethal in overdose because it induces cardiac conduction delays, ventricular dysrhythmias, hypotension, coma and seizure that may be refractory to even the most aggressive management (Reichert et al., 2014; Paksu et al., 2015). Previous studies have shown that these effects arise from the blockage of voltage-dependent sodium channels providing a fast flow of sodium $\left(\mathrm{Na}^{+}\right)$into the cell in addition to antagonistic effects on many receptors (Paksu et al., 2015).

The selective serotonin reuptake inhibitors (SSRIs), of which fluoxetine (Prozac ${ }^{\circledR}$ ) is a prototype, achieve their clinical effect through inhibiting serotonin reuptake and increasing central and peripheral serotonin level (Paksu et al., 2014). It is structurally unlike TCAs, without anticholinergic or antihistaminic effects. It also has little adrenergic receptor blockade activity and therefore does not cause the life-threatening toxicity seen with TCAs. Consequently, they have become the largest class of medications prescribed and have increasingly replaced TCAs for treatment of depression (Fitzgerald and Bronstein, 2013). Previous report have suggested that overdose of fluoxetine results in a benign course (Borys et al., 1992). The largest published case series of fluoxetine overdoses found that the most common effects were tachycardia, drowsiness, tremor, nausea, and vomiting, and concluded that such overdoses typically are minimally toxic (Phillips et al., 1997).

However, seizure, cardiac conduction abnormalities and even fatalities have been reported with fluoxetine ingestions, especially in the presence of other co-ingested drugs or confounding factors (Braitberg and Curry, 1995; Gross et al.,1998; Rajamani et al., 2006; Beaune et al., 2015). Moreover, one of the potentially fatal complications encountered with fluoxetine overdose is serotonin syndrome (a triad of mental-status changes, neuromuscular abnormalities, and autonomic disturbances) resulting from excessive central and peripheral serotonergic activity (Shah and Jain, 2016).

Cardiac and neurological toxicity after TCAs overdose is well known because of the considerable clinical experience. Unlike TCAs, there is much less clinical experience with SSRIs in overdose (Phillips, et al., 1997).

As the principal indication for prescribing these agents is depression, which is a strong risk factor for suicidal overdose, so their clinical toxicity is of considerable medical importance. In addition, there is an absence of early clinical and laboratory findings in identifying the patients at risk of life-threatening complications during the poisoning.
So the aim of this study is to compare acute toxicity of fluoxetine versus that of amitriptyline among patients admitted to the Poison Control Centre, Ain Shams University and to investigate some predictive factors for the development of complications in such cases.

\section{Patients and methods}

A prospective study was conducted in the Poison Control Centre; Ain Shams University Hospitals (PCCASUH) during the period between January 2013 and December 2015.The patients were included in this study if they presented with history of acute toxicity of amitriptyline or fluoxetine. Exclusion criteria included any patient with previous history of neurological, cardiovascular, pulmonary, liver, renal or endocrinal diseases. In addition to pregnancy, co-ingestion of proconvulsant, antiepileptic and/or cardio-toxic drugs. An informed written consent was taken from each patient or his/her guardian, in addition, to head of PCC and Ethical Committee approval.

\section{Methods}

The patients were divided into two groups: patients with acute fluoxetine toxicity only and patients with acute amitriptyline toxicity only.

\section{Data collection}

$>$ Descriptive variables: age, gender, amount taken, delay time and manner of toxicity: suicidal, accidental (iatrogenic) or other.

\section{$>$ Clinical variables:}

- Vital signs: heart rate, mean blood pressure, temperature, respiratory rate.

\section{- Cardiovascular:}

- Baseline 12-lead electrocardiogram was recorded for calculating mean QRS duration, QT interval and corrected QT (QTc) on admission.

- Monitoring for cardiac arrhythmias.

- Neurological: level of consciousness, assessed by Glasgow coma scale (GCS) (Reith et al., 2016), pupil size and reactivity, seizures, and symptoms of serotonin toxicity according to Hunter serotonin toxicity criteria: decision rules (Dunkley et al.,2003).

In the presence of a serotonergic agent:

1. IF spontaneous clonus (yes) THEN serotonin toxicity (YES)

2. ELSE IF inducible clonus (yes) AND [agitation (yes) OR diaphoresis (yes)] THEN serotonin toxicity (YES)

3. ELSE IF (ocular clonus (yes) AND [agitation (yes) OR diaphoresis(yes)] THEN serotonin toxicity(YES)

4. ELSE IF tremor (yes) AND hyper-reflexia (yes) THEN serotonin toxicity (YES)

5. ELSE IF hypertonic (yes) AND temperature > $38^{\circ} \mathrm{C}$ AND [ocular clonus (yes) OR inducible clonus (yes)] then serotonin toxicity(YES) 


\section{laboratory variables:}

- Serum electrolytes levels: sodium $\left(\mathrm{Na}^{+}\right)$ ,potassium $\left(\mathrm{K}^{+}\right)$, calcium $\left(\mathrm{Ca}^{+}\right)$and magnesium $\left(\mathrm{mg}^{+}\right)$were determined by flame absorption photometer JenwayPFP7 (Bibby Scientific Limited OSA, UK) (Rothrock et al.,1997).

- Random blood glucose level. Done by calorimetric method (Kaplan, 1984).

$>$ The outcome variables: proportion of cases with:

- Cardiac arrhythmias.

- $\quad$ QRS $\geq 100$. (Paksu et al., 2014).

- $\quad$ QTc $\geq 440$. (Funk and Bostwick, 2013).

- Seizures.

- $\quad$ GCS $\leq 10$ (Reith et al., 2016).

- Serotonin toxicity.

- ICU admission.

- $\quad$ Length of stay in ICU.

- Length of hospital stay.

- Survival and non survival.

Measurement of QT intervals and calculation of QTc: QTc was calculated in all the patients as described by Van de Loo et al. (1994). R-R and QT intervals were measured in the 12 leads. The QT intervals were measured in each lead from beginning of the depolarization of QRS complex to the end of the T wave. Each measurement was taken as the mean value of 2 to 3 consecutive RR and QT intervals. QT was corrected in accordance with the heart rate using Bazett's formula (corrected QT (QTc) $=\mathrm{QT} / \sqrt{ } \mathrm{R}-\mathrm{R}$ interval) in milliseconds. This traditional correction procedure is intended to obviate the dependence of QT interval on heart rate. In the case of interfering premature complexes, the lead concerned was not included in the subsequent analysis.

All patients received supportive medical treatment. This followed an approved standard protocol, which was dictated by the patient's clinical condition (Body et al., 2011).

\section{Statistical Analysis}

The statistical analysis was performed using a standard SPSS (Statistical Package for Social Science) software package, version 21 (Chicago, IL). Data were expressed as (mean $\pm \mathrm{SD}$ ), numbers (\%) and relative risk with $95 \%$ confidence intervals. Student's $t$-test was used to analyze the parametric data, discrete variables were analyzed using chi-square test $\left(\chi^{2}\right)$,logistic regression models were used to predict the risk factors for seizure and specificity, sensitivity, positive predictive value (PPV) and negative predictive value (NPP) were measured for the independent risk factors, with $\mathrm{p}<0.05$ considered statistically significant (Taylor, 1990).

\section{Results}

The present study included 31 patient ingested fluoxetine alone and 49 patients ingested amitriptyline alone.

As regards the descriptive variables of patients (table 1), there was highly significant increase of the age and amount of drug ingested in amitriptyline group compared to fluoxetine group. There was insignificant difference on comparing both groups as regards gender and delay time and all cases in both groups were due to suicidal overdose.

As regards the cardiovascular variables on admission (table 2), there was insignificant difference in mean values of heart rate and mean blood pressure between both groups. A highly significant increase of mean QRS and QTc intervals were found in amitriptyline group when compared with fluoxetine group. None of the patients in both groups developed cardiac arrhythmias.

As regards the neurological variables on admission (table 2), significant decrease in the mean values of GCS and a highly significant increase of percentage of patients with mydriasis was found in amitriptyline group. A highly significant increase of percentage of tremors, clonus, hyper-reflexia and diaphoresis was found in fluoxetine group. There was insignificant difference in percentage of cases with agitation between both groups.

As regards the laboratory variables on admission (table 3). There was a significant decrease of serum sodium in amitriptyline group when compared with fluoxetine group. A non significant difference was found as regards serum potassium, calcium, magnesium and blood glucose levels between both groups.

On comparing the proportion of outcome variables between both groups (table 4), there was insignificant difference as regards the percentage of cases with seizures and survival. There was significant increase in percentage of cases with QRS $\geq 100$, QTc $\geq 440$, GCS $\leq 10$ and ICU admission in amitriptyline group compared to fluoxetine group. There was a highly significant increase of cases with serotonin toxicity in fluoxetine group compared to amitriptyline group. Relative risk for the outcome data for fluoxetine versus amitriptyline confirm the differences and give an indication of the strength of those differences. A significant increase of length of stay in ICU and length of hospital stay was observed in amitriptyline group compared to fluoxetine group of patients (table 5).

On comparing patients who developed seizures with patients without seizures after acute amitriptyline toxicity (table 6), there was insignificant difference between both groups as regards the mean values of age. There was a highly significant increase in the amount of drug intake, QRS, QTc interval duration and length of hospital stay and highly significant decrease of mean GCS and serum sodium level in those who developed seizures.

By applying logistic regression analysis to examine the effect of factors like amount of drug intake, QRS $\geq 100, \mathrm{QTc} \geq 440, \mathrm{GCS} \leq 10$ and presence of hyponatremia on the development of seizures, in amitriptyline group of patients. QRS $\geq 100 \mathrm{msec}$, QTc $\geq 440$ msec and GCS $\leq 10$ were identified as independent risk factors (table 7). QRS $\geq 100$ showed (sensitivity 97\%, specificity 71\%, PPV 67\% and NPV 97\%); QTc $\geq 440$ showed (sensitivity 65\%, specificity $64 \%$, PPV55\% and NPV 68\%) and GCS $\leq 10$ showed 
(sensitivity 86\%, specificity 71\%, PPV 60\% and NPV 80\%) (Table 8).

On comparing patients who developed seizures with patients without seizures after acute fluoxetine toxicity (table 9) there was a highly significant increase in the amount of drug intake, QTc interval duration, percentage of cases with serotonin toxicity and length of hospital stay and highly significant decrease of mean GCS. There was insignificant difference between both group as regards the mean values of age, mean QRS duration and serum sodium level on admission.
By applying logistic regression analysis to examine the effect of factors like amount of drug intake, and QTc $\geq 440$, GCS $\leq 10$ and serotonin toxicity on the development of seizures in fluoxetine group of patients. QTc $\geq 440$, GCS $\leq 10$ and serotonin toxicity were identified as independent risk factors (table10). QTc interval $\geq 440$ showed (sensitivity $62 \%$, specificity 82\%, PPV 55\% and NPV 86\%); GCS $\leq 10$ showed (sensitivity $72 \%$, specificity $84 \%$, PPV $60 \%$ and NPV 91\%) and serotonin toxicity showed (sensitivity 100\%,specificity 86\%, PPV72\% and NPV 100\%) (Table11).

Table 1: Student " $t$ " test analysis of age, amount of drug taken, delay time and Chi square test analysis $\left(\chi^{2}\right)$ of the gender and manner of poisoning between fluoxetine and amitriptyline groups of patients.

\begin{tabular}{|l|l|l|l|}
\hline & \multicolumn{1}{|c|}{$\begin{array}{c}\text { Fluoxetine group } \\
(\mathbf{n = 3 1 )}\end{array}$} & \multicolumn{1}{|c|}{$\begin{array}{c}\text { Amitriptyline group } \\
(\mathbf{n = 4 9 )}\end{array}$} & \multicolumn{1}{c|}{$\mathbf{p}$} \\
\hline Age (years) $(\mathrm{M} \pm \mathrm{SD})$ & $28.32 \pm 9$ & $40.3 \pm 15.5$ & $<0.01$ \\
\hline $\begin{array}{l}\text { Gender } \\
\text { female } \\
\text { male }\end{array}$ & $25(80.6 \%)$ & $36(73.5 \%)$ & $>0.05 \#$ \\
\hline Amount taken (mg) & $6(19.4 \%)$ & $13(26.5 \%)$ & $<0.01$ \\
\hline Delay time (M \pm SD)(hours) & $809.7 \pm 126.6$ & $911 \pm 62$ & $>0.05$ \\
\hline $\begin{array}{l}\text { Manner of poisoning } \\
\text { Suicide }\end{array}$ & $3.28 \pm 0.82$ & $3.65 \pm 0.9$ & $>0.05 \#$ \\
\hline
\end{tabular}

$\# P=$ Chi square test, $(M \pm S D)=$ mean \pm standard deviation, $P>0.05$ non significant difference, $P<0.01$ highly significant difference.

Table2: Student " $t$ " test analysis of mean heart rate, mean blood pressure, QRS duration, corrected QT interval ( QTc) and Glasgow coma scale (GCS), and Chi square test analysis $\left(\chi^{2}\right)$ of percentage of mydriasis, tremors, clonus, hyper-reflexia, agitation and diaphoresis between fluoxetine and amitriptyline groups of patients.

\begin{tabular}{|c|c|c|c|}
\hline & $\begin{array}{c}\text { Fluoxetine group } \\
(\mathbf{n}=31)\end{array}$ & $\begin{array}{l}\text { Amitriptyline group } \\
(\mathrm{n}=49)\end{array}$ & $\mathbf{p}$ \\
\hline \multicolumn{4}{|c|}{ Cardiovascular: } \\
\hline Heart rate $(\mathrm{bpm})(\mathrm{M} \pm \mathrm{SD})$ & $113.3 \pm 21.6$ & $115 \pm 22$ & $>0.05$ \\
\hline $\begin{array}{l}\text { Mean blood } \\
\text { pressure } \\
(\mathrm{M} \pm \mathrm{SD})\end{array}$ & $93 \pm 8.5$ & $89 \pm 10$ & $>0.05$ \\
\hline $\begin{array}{l}\text { QRS duration (msec) } \\
(\mathrm{M} \pm \mathrm{SD})\end{array}$ & $91.8 \pm 4.2$ & $105.67 \pm 14.9$ & $<0.01$ \\
\hline QTc (msec) (M \pm SD) & $409 \pm 45.4$ & $458.18 \pm 82$ & $<0.01$ \\
\hline \multicolumn{4}{|c|}{ Neurological } \\
\hline GCS $(\mathrm{M} \pm \mathrm{SD})$ & $11.1 \pm 3.1$ & $9.3 \pm 4$ & $<0.05$ \\
\hline Mydriasis & $5(16 \%)$ & $45(91.8 \%)$ & $<0.01 \#$ \\
\hline Tremors & $9(29 \%)$ & 0 & $<0.01 \#$ \\
\hline Clonus & $11(35.5 \%)$ & 0 & $<0.01 \#$ \\
\hline Hyper-reflexia & $11(35.5 \%)$ & $2(4 \%)$ & $<0.01 \#$ \\
\hline Agitation & $11(35.5 \%)$ & $13(26.5 \%)$ & $>0.05 \#$ \\
\hline Diaphoresis & $7(22.6 \%)$ & 0 & $<0.01 \#$ \\
\hline
\end{tabular}

$(\mathrm{bpm})=$ beat per minute, msec $=$ milliseconds, $(M \pm S D)=$ mean \pm standard deviation,

$\# P=$ Chi square test, $P>0.05$ non significant difference, $P<0.01$ highly significant difference.

Table 3: Student "t" test analysis of serum sodium, potassium, calcium, magnesium and random blood glucose levels between fluoxetine and amitriptyline groups of patients on admission

\begin{tabular}{|l|l|l|c|}
\hline & Fluoxetine group(n=31) & Amitriptyline group(n=49) & p \\
\hline Serum sodium $(\mathrm{mEq} / \mathrm{L})$ & $141.6 \pm 4.1$ & $136.3 \pm 6.5$ & $<0.05$ \\
\hline Serum potassium $(\mathrm{mEq} / \mathrm{L})$ & $3.74 \pm 0.34$ & $3.68 \pm 0.35$ & $>0.05$ \\
\hline Serum calcium $(\mathrm{mg} / \mathrm{dl})$ & $8.9 \pm 1.1$ & $8.5 \pm 0.9$ & $>0.05$ \\
\hline Serum magnesium(mg/dl) & $2.4 \pm 0.33$ & $2.3 \pm 0.5$ & $>0.05$ \\
\hline Random blood glucose $(\mathrm{mg} / \mathrm{dL})$ & $113.9 \pm 31.8$ & $112.57 \pm 30.5$ & $>0.05$ \\
\hline
\end{tabular}

$(M \pm S D)=$ mean \pm standard deviation, $P>0.05$ non significant difference, $P<0.05$ significant difference. 
Table 4: Chi-square test $\left(\chi^{2}\right)$ and relative risk comparing percentage of outcome data (QRS $\geq 100$, corrected QT interval (QTc) $\geq 440$, seizure, Glasgow coma scale (GCS) $\leq 10$, serotonin toxicity, ICU admission and survival between fluoxetine and amitriptyline groups of patients.

\begin{tabular}{|l|l|l|l|l|}
\hline & $\begin{array}{l}\text { Fluoxetine group } \\
(\mathbf{n = 3 1 )} \mathbf{( \% )}\end{array}$ & $\begin{array}{l}\text { Amitriptyline group } \\
\mathbf{( n = 4 9 )}(\mathbf{\% )}\end{array}$ & $\begin{array}{l}\text { Relative risk } \\
\mathbf{( 9 5 \%} \text { Confidence } \\
\text { interval) }\end{array}$ & p \\
\hline QRS $\geq 100 \mathrm{msec}$ & 0 & $27(55 \%)$ & $0.01(0.007-0.2)$ & $<0.01$ \\
\hline QTc $\geq 440 \mathrm{msec}$ & $10(32.25 \%)$ & $28(57 \%)$ & $0.36(0.14-0.9)$ & $<0.05$ \\
\hline Seizure & $8(25.81 \%)$ & $18(36.73 \%)$ & $0.45(0.22-1.6)$ & $>0.05$ \\
\hline GCS $\leq 10 \mathrm{msec}$ & $10(32.25 \%)$ & $22(44.9 \%)$ & $0.79(0.27-1.7)$ & $<0.05$ \\
\hline Serotonin toxicity & $11(35.5 \%)$ & 0 & $55.5(3.12-987.6)$ & $<0.01$ \\
\hline ICU admission & $10(32.25 \%)$ & $27(55 \%)$ & $0.45(0.18-1.13)$ & $<0.05$ \\
\hline Survival & $31(100 \%)$ & $49(100 \%)$ & & $>0.05$ \\
\hline
\end{tabular}

msec=milliseconds,$P>0.05$ non significant difference, $P<0.05$ significant difference, $P<0.01$ highly significant difference.

Table 5: Student " $t$ ”" test comparing outcome data (length of stay in ICU and length of hospital stay) between fluoxetine and amitriptyline groups of patients.

\begin{tabular}{|l|l|l|l|}
\hline & \multicolumn{1}{|c|}{$\begin{array}{c}\text { Fluoxetine group } \\
(\mathbf{n = 3 1 )}\end{array}$} & \multicolumn{1}{|c|}{$\begin{array}{c}\text { Amitriptyline group } \\
\text { (n=49) }\end{array}$} & p \\
\hline Length of stay in ICU (hours) & $24 \pm 12$ & $36 \pm 12$ & $<0.01$ \\
\hline $\begin{array}{l}\text { Length of hospital stay } \\
\text { (hours) }\end{array}$ & $42.5 \pm 14$ & $52.4 \pm 24$ & $<0.05$ \\
\hline
\end{tabular}

All data presented as $(M \pm S D)=$ mean \pm standard deviation, $P<0.05$ significant difference, $P<0.01$ highly significant difference.

Table 6: Student “ $t$ " test analysis of age, amount taken, QRS duration, corrected QT interval (QTc), Glasgow coma scale (GCS), serum sodium level and length of hospital stay between patients with and without seizure after ingesting amitriptyline.

\begin{tabular}{|c|c|c|c|}
\hline & $\begin{array}{c}\text { Amitriptyline with } \\
\text { seizure }(n=18)\end{array}$ & $\begin{array}{c}\text { Amitriptyline without } \\
\text { seizure }(n=31)\end{array}$ & $\mathbf{p}$ \\
\hline 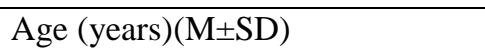 & $43.5 \pm 14.5$ & $38.9 \pm 16$ & $>0.05$ \\
\hline Amount taken(mg) $(\mathrm{M} \pm \mathrm{SD})$ & $1365.7 \pm 142.5$ & $501 \pm 82$ & $<0.01$ \\
\hline $\mathrm{QRS}(\mathrm{msec})(\mathrm{M} \pm \mathrm{SD})$ & $119.6 \pm 4.6$ & $97.5 \pm 12.5$ & $<0.01$ \\
\hline QTc (msec) (M \pm SD) & $525.7 \pm 59.9$ & $418 \pm 65$ & $<0.01$ \\
\hline GCS $(\mathrm{M} \pm \mathrm{SD})$ & $5.9 \pm 1.6$ & $12.1 \pm 3$ & $<0.01$ \\
\hline Serum sodium $(\mathrm{mEq} / \mathrm{L})(\mathrm{M} \pm \mathrm{SD})$ & $130.7 \pm 4.6$ & $138.9 \pm 5.7$ & $<0.01$ \\
\hline $\begin{array}{l}\text { Length of hospital stay } \\
\text { (hours) (M } \pm \text { SD) }\end{array}$ & $74 \pm 13.6$ & $36.7 \pm 6$ & $<0.01$ \\
\hline
\end{tabular}

Table 7: Logistic regression analysis to determine the predictive markers for developing seizures in amitriptyline group of patients.

\begin{tabular}{|l|l|l|}
\hline & \multicolumn{1}{|c|}{ r } & \multicolumn{1}{c|}{ P } \\
\hline Amount taken(mg) & 0.25 & $>0.05$ \\
\hline QRS $\geq 100 \mathrm{msec}$ & 3.7 & $<0.05$ \\
\hline $\mathrm{QTc} \geq 440 \mathrm{msec}$ & 0.7 & $<0.05$ \\
\hline $\mathrm{GCS} \leq 10$ & -0.57 & $<0.05$ \\
\hline Sodium level on admission(mEq/L) & 0.02 & $>0.05$ \\
\hline $\begin{array}{l}\text { msec=milliseconds ,r, correlation coefficient, GCS=Glasgow coma score, P> } 0.05 \text { non significant } \\
\text { difference, P }<0.05 \text { significant difference. }\end{array}$
\end{tabular}

Table 8: Sensitivity, specificity, positive predictive value (PPV) and negative predictive value (NPV) of QRS interval, corrected QT interval QTc) and Glasgow coma scale (GCS) in amitriptyline associated with seizures group of patients.

\begin{tabular}{|l|l|l|l|l|}
\hline & \multicolumn{1}{|c|}{ Sensitivity } & Specificity & PPV & NPP \\
\hline QRS $\geq 100 \mathrm{msec}$ & $97 \%$ & $71 \%$ & $67 \%$ & $97 \%$ \\
\hline QTc interval $\geq 440 \mathrm{msec}$ & $65 \%$ & $64 \%$ & $55 \%$ & $68 \%$ \\
\hline GCS $\leq 10$ & $86 \%$ & $71 \%$ & $60 \%$ & $80 \%$ \\
\hline
\end{tabular}

msec $=$ milliseconds 
Table 9: Student “t”" test analysis of age, amount taken, QRS duration, corrected QT interval (QTc), Glasgow coma scale (GCS), serum sodium level and length of hospital stay and Chi square test analysis $\left(\chi^{2}\right)$ of percentage of serotonin toxicity between patients with and without seizure after ingesting fluoxetine groups.

\begin{tabular}{|l|l|l|l|}
\hline & $\begin{array}{l}\text { Fluoxetine with seizure } \\
(\mathrm{n}=8)\end{array}$ & $\begin{array}{l}\text { Fluoxetine without seizure } \\
(\mathrm{n}=23)\end{array}$ & $\mathrm{p}$ \\
\hline Age (years)(M $\pm \mathrm{SD})$ & $26.6 \pm 5.3$ & $30.47 \pm 9.5$ & $>0.05$ \\
\hline Amount taken $(\mathrm{mg})(\mathrm{M} \pm \mathrm{SD})$ & $1497.5 \pm 48.4$ & $570.4 \pm 44.8$ & $<0.01$ \\
\hline QRS(msec) $(\mathrm{M} \pm \mathrm{SD})$ & $92.38 \pm 5.04$ & $91.7 \pm 3.9$ & $>0.05$ \\
\hline QTc $(\mathrm{msec})(\mathrm{M} \pm \mathrm{SD})$ & $452 \pm 19.7$ & $394.5 \pm 42.7$ & $<0.01$ \\
\hline GCS $(\mathrm{M} \pm \mathrm{SD})$ & $7.25 \pm 1$ & $12.39 \pm 2.4$ & $<0.01$ \\
\hline Serum sodium(mEq/L) $(\mathrm{M} \pm \mathrm{SD})$ & $142.6 \pm 4.5$ & $141.1 \pm 3.2$ & $>0.05$ \\
\hline Serotonin toxicity & $8(100 \%)$ & $3(13 \%)$ & $<0.01 \#$ \\
\hline $\begin{array}{l}\text { Length of hospital stay } \\
\text { (hours) }(\mathrm{M} \pm \mathrm{SD})\end{array}$ & $69 \pm 8.5$ & $36 \pm 2.1$ & $<0.01$ \\
\hline
\end{tabular}

msec $=$ milliseconds,$\# P=$ Chi square test, $(M \pm S D)=$ mean \pm standard deviation, $P>0.05$ non significant difference, $P<$ 0.01 highly significant difference.

Table10: Logistic regression analysis to determine the predictive markers for developing seizure in fluoxetine group of patients.

\begin{tabular}{|l|l|l|}
\hline & \multicolumn{1}{|c|}{$\mathbf{r}$} & \multicolumn{1}{c|}{ P } \\
\hline Amount taken & 0.19 & $>0.05$ \\
\hline QTc $\geq 440$ msec & 0.62 & $<0.05$ \\
\hline GCS $\leq 10$ & -0.64 & $<0.05$ \\
\hline Serotonin toxicity & 4.24 & $<0.05$ \\
\hline
\end{tabular}

msec =milliseconds, $r$, correlation coefficient, GCS=Glasgow coma score, $P>0.05$ non significant difference, $P<0.05$ significant difference.

Table 11: Sensitivity, specificity, positive predictive value (PPV) and negative predictive value (NPV) of corrected QT interval (QTc), Glasgow coma scale (GCS) and serotonin toxicity in fluoxetine associated seizure group of patients.

\begin{tabular}{|l|l|l|l|l|}
\hline & \multicolumn{1}{|c|}{ Sensitivity } & \multicolumn{1}{|c|}{ Specificity } & \multicolumn{1}{|c|}{ PPV } & \\
\hline $\begin{array}{l}\text { QTc interval } \\
\text { mesc }\end{array}$ & $62 \%$ & $82 \%$ & $55 \%$ & $86 \%$ \\
\hline GCS $\leq 10$ & $72 \%$ & $84 \%$ & $60 \%$ & $91 \%$ \\
\hline Serotonin toxicity & $100 \%$ & $86 \%$ & $72 \%$ & $100 \%$ \\
\hline
\end{tabular}

msec $=$ milliseconds.

\section{Discussion}

As regards the descriptive variables, the present study showed a significant increase in the age and amount of drug in amitriptyline (Tryptizol) intoxicated patients compared to fluoxetine (Prozac) intoxicated patients. This may be due to amitriptyline low price, packaging difference where there is increase number of tablets per pack of amitriptyline in comparison to fluoxetine. Also, as TCAs being more effective anti-depressant than SSRIs, that may explain the significant increase in age among amitriptyline group in comparison with the fluoxetine group in this study.

Concerning the clinical variables, the present study showed a highly significant increase in the means of QRS and QTc intervals in amitriptyline group when compared with fluoxetine group. This is similar to previous studies that revealed that TCAs shows higher incidence rates than SSRIs in inducing cardiovascular insult (Phillips et al., 1997; Whyte et al., 2003; Funk and Bostwick, 2013; Spindelegger et al., 2014).

The cardiovascular effects and toxicity of amitriptyline result from the combination of fast cardiac sodium $\left(\mathrm{Na}^{+}\right)$channel blockade, alphaadrenergic blockade, anti-cholinergic effects, and direct myocardial depression (Gheshlaghi et al., 2012; Paksu et al., 2015).

While the most human clinical studies with SSRIs like fluoxetine and others showed significant advantages over TCAs in producing fewer cardio-toxic effects. These newer compounds are believed to exhibit lower risk of inducing cardio-toxicity and a higher margin of safety in acute overdose than TCAs (Cheer and Goa, 2001). However, although fluoxetine is 
chemically unrelated to TCA agents yet it was associated with a non-specific, insignificant prolongation of QT interval irrespective of age (Pacher and Kecskemeti, 2004). In one case report, QTc reached $625 \mathrm{msec}$ in a patient who took an overdose of fluoxetine and was attributed to the extended potassium $\left(\mathrm{K}^{+}\right)$channel blocking effect of fluoxetine and its active metabolite norfluoxetine (Rajamani et al., 2006). The mechanism of this slight QTc prolongation by fluoxetine is not known. However, serotonin augments central parasympathetic tone to the heart, and this action may cause slight QTc prolongation (Phillips et al., 1997).

Regarding the neurological manifestation in this study, a significant decrease in the mean values of GCS and a highly significant increase of proportion of cases with mydriasis was found in amitriptyline group. This is attributed to TCA-induced neurotoxicity including gama-aminobutyric acid receptor antagonism, neuronal $\mathrm{Na}^{+}$channel blockage, central anti-cholinergic and anti-histaminergic activities, and the effects of biogenic amines (Mills, 2005; Paksu et al., 2014).

Previous clinical study showed that fluoxetine causes significantly fewer anti-cholinergic, antihistaminergic, sedating, altered conscious level and cardio-toxic side effects when compared to TCAs (Cheer and Goa, 2001).

On the other hand, in this study regarding the percentages of cases with serotonin toxicity in fluoxetine versus amitriptyline groups were; tremors (29\% vs 0), clonus (35.5\% vs 0), hyper-reflexia (35.5\% vs $4 \%$ ), agitation (35.5\% vs $26.5 \%$ ) and diaphoresis (22.6\% vs 0) respectively.

Fluoxetine exert its action through inhibiting serotonin reuptake and increasing serotonin level (5HT) centrally and peripherally (Fitzgerald and Bronstein, 2013). Previously,Wu and Deng, 2011 described a fatal serotonin toxicity case caused by fluoxetine and a co-ingestant with clinical features that included coma, mydriasis, hyperthermia, tremor, hyper-reflexia that eventually led to rhabdomyolysis, renal failure and respiratory insufficiency. Many cases of serotonin toxicity occur in patients who have ingested drug combinations that synergistically increase synaptic 5-HT, such as the interaction between MAOIs and SSRIs, which can cause life-threatening serotonin toxicity (Rui et al., 2014). However, serotonin toxicity has been reported following ingestion of a single agent and occurs in 16\% of patients ingesting SSRIs in overdose (Fraser and South, 1999; Whyte and Dawson, 2002; Monte et al., 2010).

Serotonin toxicity results from an increase in the intra-synaptic concentrationof 5-HT in the CNS. Thus it is a concentration-dependent toxicity that can develop in any individual, rather than an idiosyncratic reaction to a drug (Prakash and Rathore, 2016; Shah and Jain, 2016).
Previously it was described as a triad of clinical features consisting of autonomic signs, neuromuscular changes and altered mental status (Lane and Baldwin, 1997).These ill-defined clinical features of serotonin syndrome have lead to an inaccurate diagnosis of serotonin toxicity and resulted in increasing confusion about which medications can cause serotonin toxicity, with misleading case reports that misattribute serotonin toxicity to a number of drugs that are unlikely cause increased levels of CNS 5-HT (Isbister et al.,2001a; Duggal and Fetchko, 2002 ;Isbister et al.,2003). Moreover, the ill-defined features of serotonin toxicity have misled many authors into suggesting that it is similar to neuroleptic malignant syndrome (NMS) and should be a differential diagnosis for it which is clearly not the case (Isbister et al.,2001b). Hence, such confusion uncovered the defect in the parameters to reach clinical diagnosis. In 2003, Dunkley et al. developed criteria for the diagnosis of serotonin toxicity using decision rules, in patients with overdoses of a single purely serotonergic drug. These rules are simple, sensitive and specific, and involve the use of only a few well-defined clinical features like: clonus, agitation, diaphoresis, tremor, hyper-reflexia, hypertonia and temperature and concluded that, serotonin excess is best considered a spectrum of toxicity, rather than a distinct clinical entity (syndrome).

In the present study, hyperthermia did not occur in any of the patients of fluoxetine-alone overdoses, this may be because it occurs with severe cases involving combinations of serotonergic agents (Power et al., 1995 ; Dunkley et al., 2003).

In the current study, the serum $\mathrm{Na}^{+}$level was significantly less in amitriptyline group when compared with fluoxetine group, however, it was in the normal reference range in both groups.

As regards the outcome data in this work, it revealed higher percentage of cases with GCS $\leq 10$, QRS $\geq 100 \mathrm{msec}$, QTc $\geq 440 \mathrm{msec}$ and ICU admission, as well as longer ICU and hospital stay time among the amitriptyline compared to fluoxetine groups of patients and a higher incidence of serotonin toxicity among fluoxetine compared to amitriptyline groups of patients. This is in accordance with Whyte et al. (2003) and Abadie et al. (2015) who believed that TCAs overdoses are much more likely to be with lower GCS and consequently require ICU admission, and much less likely to have serotonin toxicity than SSRIs. While, SSRIs overdoses were less likely to cause tachycardia, hypotension, and prolongation of the QRS and QTc than TCAs. Also, SSRIs overdosed patients spent significantly less time in hospital than TCAs patients

In this study, survival rate was equal between the two drug groups with no deaths reported. This can be explained by the early diagnosis and aggressive successful management regimen conducted in the PCC. It is believed that the majority of patients with antidepressants toxicity recover well with supportive 
therapy (Paksu et al., 2014). Although, in studies of mortality from overdose of antidepressants, the numbers of deaths per million prescriptions were lower for SSRIs than for TCAs (Whyte et al., 2003; McKenzie and McFarland, 2007).

In this study there was no significant difference in the incidence of seizure occurrence between both groups. Seizure is considered one of the potentially lethal complications of antidepressants toxicity that can lead to rhabdomyolysis, renal failure and eventually death (Olgun et al., 2009).

By comparing patients with amitriptyline toxicity who developed seizure with those who did not, it was found that there was highly significant increase in the amount ingested, QRS and QTc durations and hospital stay time and highly significant decrease in GCS and $\mathrm{Na}^{+}$level in those with seizure complication. Also, by applying logistic regression analysis to determine the predictive factors to develop seizure, a positive correlation was found with QRS $\geq 100 \mathrm{msec}$, QTc $\geq 440 \mathrm{msec}$ and GCS $\leq 10$ with sensitivityspecificity (97\% -71\%, 65\%-64\%, 86\% -71\%) respectively. While the amount of drug and $\mathrm{Na}^{+}$level were not correlated with the incidence of seizure.

As regards the impact of the amount ingested, amitriptyline toxicity often arises at doses exceeding $10 \mathrm{mg} / \mathrm{kg}$ (Olgun et al., 2009). However, lower doses can cause serious toxicity (Woolf et al., 2007). Accordingly, estimated amount of drug taken based on history taking alone may be misleading. In addition, correlation between amount taken, serum level of drugs and severity of clinical findings which includes occurrence of seizure is weak and the predictive value is unreliable (Hulten et al., 1992).

Hyponatremia, on the other hand, is the most common electrolyte disturbance encountered in critically poisoned patients (Singhi, 2004). The condition is brought about by $\mathrm{Na}^{+}$loss due to vomiting during acute intoxication, gastric lavage with hypotonic fluids, the use of hypotonic fluids, impaired fluid excretion, but most importantly, is inappropriate secretion of anti-diuretic hormone due to critical illness (Paksu et al., 2015). Hyponatremia was detected in $26.9 \%$ and in $25 \%$ of TCAs poisoning cases in previous studies by Olgun et al. (2009); Gheshlaghi et al. (2012) respectively. There is conflicting information about serum $\mathrm{Na}^{+}$level or hyponatremia playing a role in causing or resulting from seizures. However, hyponatremia is one of the factors well known to precipitate convulsion (Chawla et al., 2011). Paksu et al. (2014) noticed a strong association between the presence of hyponatremia and the development of serious complications including seizure in amitriptyline overdose. The authors believe that the appearance of the drug side effects, mainly via the $\mathrm{Na}^{+}$channels blockage, makes this result more meaningful.

Prolonged QRS and QTc durations, are the most common findings in amitriptyline toxicity that may proceed to lethal dysrhythmia as ventricular tachycardia, supra-ventricular tachycardia and torsad de points (TDP). None of the patients in this study experienced cardiac dysrhythmia, cardiac arrest or TDP in both groups despite the prolonged QTc duration. This can be explained by the fact that, TDP usually occurs after bradycardia, which is not a finding commonly encountered in acute intoxication (Gheshlaghi et al., 2012). Also, Not all drugs that prolong the QTc interval produce TDP and the link between the lengthening of QT interval and TDP is seemingly very complex and affected by several factors including electrolyte imbalance, age, gender, underlying myocardial disease and co-ingestant (Pacher and Kecskemeti, 2004).

Previous studies have explored the relationship between ECG findings and development of serious complications as seizure in TCAs toxicity (Bailey et al., 2004; Eyer et al., 2009; Olgun et al., 2009). It was reported that QRS duration $>100 \mathrm{msec}$ is predictive for seizures. The prolongation of QTC duration is usually associated with widening of QRS interval in amitriptyline poisoning and both intervals were found to be associated with life-threatening serious complications and were considered good predictors of seizure development in a recent study by Paksu et al. (2014).

Patients with acute TCAs intoxication and wide QRS complex usually have changes in their level of consciousness and GCS. The most common symptoms were conscious level changes (81.52\%) and mydriasis (64.1\%) in a study by Gheshlaghi et al. (2012). Similarly, low GCS on admission was identified as an independent risk factor for the development of life-threatening complications such as seizure and a predictor of bad prognosis after amitriptyline poisoning (Paksu et al., 2014). Furthermore, the increased incidence of seizure reported together with low GCS was found in a study of TCAs overdose by Calkins et al. (2003).

Regarding patients with fluoxetine toxicity that developed seizure in comparison with those who did not, it was found that there was highly significant increase in the amount ingested, QTc duration, percentage of serotonin toxicity and hospital stay time and highly significant decrease in GCS in those with seizure. Also, by applying logistic regression analysis to determine the predictive factors of seizure occurrence, a positive correlation was found with QTc $\geq 440$ msec, GCS $\leq 10$ and incidence of serotonin toxicity with sensitivity-specificity (62\%-82\%, 72\% $84 \%, 100 \%$ - 86\%) respectively.

The mechanisms underlying generalized seizures after fluoxetine toxicity are unclear, but massive increases in brain serotonin concentrations might be directly responsible (Klein-Schwartz et al., 2012). Fluoxetine as most antidepressants may display both anticonvulsant and pro-convulsant properties, with the most important determining factor being the dose (Suchard, 2008). In a study of five different SSRIs taken in overdose, fluoxetine had the lowest incidence of inducing seizure (Isbister et al., 2004). In 
this work 8 out of 31 patients (25.8\%) with fluoxetine toxicity developed seizure. Only a few cases of seizure after isolated fluoxetine overdose in normal subjects have been reported (Braitberg and Curry, 1995; Gross et al., 1998), less commonly seizure can occur with therapeutic dose and there are two case reports of seizure with fluoxetine at a dose of $20 \mathrm{mg}$ (Weber, 1989; Oke et al., 2001). While, other reports were confounded by co-ingestant and/or underlying brain disease (Weber, 1989; Hargrave et al., 1992; Prasher, 1993). Suchard (2008) believed that although most fluoxetine overdoses are benign, yet intentional, highdose fluoxetine ingestions may induce seizures. In SSRIs toxicity, prolonged hospital stay, high dosages and co-ingestion of drugs capable of lowering seizure threshold have strong association with seizure incident (Waring et al., 2008).

Although uncommon, fluoxetine causes QT interval prolongation and subsequent arrhythmias as TDP with risk of sudden death (Funk and Bostwick, 2013). A QTc $>461 \mathrm{msec}$ was noticed in a patient who suffered from convulsion episode after fluoxetine suicidal overdose (Suchard, 2008). Neely (1998) noticed that there is strong association between cardiac dysrhythmia and seizure activity in fluoxetine overdose.

Regarding the predictive values of GCS and serotonin toxicity to develop seizure, Graudins et al. (1997) noticed the occurrence of seizure in fluoxetine poisoning case which was on admission lethargic with altered level of consciousness and with QRS $>110$ msec and QTc $>458 \mathrm{msec}$. Also, seizure occurred more frequently in relation with serotonin toxicity in SSRIsexposed patients (Beaune et al., 2015). It is suggested that acute severe serotonin toxicity, can induce structural and long-standing functional changes in multiple cortical and sub-cortical brain regions that are associated with cognitive and extra pyramidal syndromes (Szólics et al., 2012). Fluoxetine overdose induced- serotonin toxicity may manifest itself as seizure (Fitzgerald and Bronstein, 2013). Hence, the prevalence of seizure might be justified.

\section{Conclusion}

Fluoxetine, although is considered safer than amitriptyline, yet it carries risks of developing complications as serotonin toxicity and seizure in acute large doses. Seizure was noted in fluoxetine toxicity to be associated with increased amount, prolonged QTc duration, low GCS and serotonin toxicity and in amitriptyline toxicity associated with increased amount, prolonged QRS and QTc durations, low GCS and hyponatremia. This study demonstrated valuable predictive risk factors for seizure being the length of QRS $\geq 100 \mathrm{msec}$ and QTc $\geq 440 \mathrm{msec}$ and GCS $\leq 10$ for amitriptyline overdose and QTc $\geq 440 \mathrm{msec}$, GCS $\leq 10$ and serotonin toxicity for fluoxetine overdose.

\section{Recommendations}

As the correlation between serum drug levels and clinical outcome is weak, and routine drug level analyses are not usually available, so it is recommended to use the aforementioned predictive risk factors to prompt early recognition of seizure potentiality and conduct successful interventions and prophylactic measures, hence decreasing morbidity and mortality rates in the clinical settings.

\section{References}

Abadie D, Rousseau V, Logerot S et al., (2015): Serotonin Syndrome: Analysis of Cases Registered in the French Pharmaco vigilance Database. J Clin Psycho pharmacol; 35(4):382-388.

Bailey B, Buckley N and Amre D (2004): A metaanalysis of prognostic indicators to predict seizures, arrhythmias or death after tricyclic antidepressant overdose. J Toxicol Clin Toxicol; 42: 877-888.

Beaune S, Curis E, Casalino E et al., (2015): Do serotonin reuptake inhibitors worsen outcome of patients referred to the emergency department for deliberate multi-drug exposure? Basic Clin Pharmacol Toxicol; 116(4):372-377.

Bek K, Ozkaya O, Mutlu B et al., (2008): Charcoal hemoperfusion in amitriptyline poisoning: experience in 20 children. Nephrology (Carlton); 13(3):193-197.

Body R, Bartram T, Azam F et al., (2011): Guidelines in Emergency Medicine Network (GEMNet): guideline for the management of tricyclic antidepressant overdose. Emerg Med J. Apr;28(4):347-68.

Borys D, Setzer S, Ling L et al., (1992): Acute fluoxetine overdose: a report of 234 cases. Am J Emerg Medicine.; 10:115-120.

Braitberg G and Curry S (1995): Seizure after isolated fluoxetine overdose. Ann Emerg Med; 26:234-237.

Calkins T, Chan T, Clark R et al., (2003): Review of pre-hospital sodium bicarbonate use for cyclic antidepressant overdose. Emerg Med J;20(5):483-486.

Chawla A, Sterns R, Nigwekar S et al., (2011): Mortality and serum sodium: do patients die from or with hyponatremia? Clin J Am Soc Nephrol; 6(5):960-965.

Cheer S and Goa K (2001): Fluoxetine: a review of its therapeutic potential in the treatment of depression associated with physical illness. Drugs;61(1):81-110.

Duggal H and Fetchko J (2002): Serotonin syndrome and atypical antipsychotics. Am J Psychiatry, 159:672-3.

Dunkley E, Isbister G, Sibbritt D et al., (2003): The Hunter Serotonin Toxicity Criteria: simple and accurate diagnostic decision rules for serotonin toxicity. Q J Med; 96:635-642. 
Eyer F, Stenzel J, Schuster T et al., (2009): Risk assessment of severe tricyclic-antidepressant overdose. Hum Exp Toxicol; 28: 511-519.

Fitzgerald K and Bronstein A (2013): Selective serotonin reuptake inhibitor exposure. Top Companion Anim Med; 28(1):13-7.

Fraser J and South M (1999): Life-threatening fluvoxamine overdose in a 4-year-old child. Intensive Care Med; 25:548.

Funk K and Bostwick J (2013): A comparison of the risk of QT prolongation among SSRIs. Ann Pharmaco ther; 47(10):1330-41.

Gheshlaghi F, Eizadi-Mood N, EmamikhahAbarghooeii S et al., (2012): Evaluation of serum sodium changes in tricyclic antidepressants toxicity and its correlation with electrocardiography, serum $\mathrm{pH}$, and toxicity severity. Adv Biomed Res; 1: 68.

Graudins A, Vossler C and Wang R (1997): Fluoxetine-induced cardio-toxicity with response to bicarbonate therapy. Am J Emerg Med; 15(5):501-503.

Gross R, Dannon P, Lepkifker E et al., (1998): Generalized seizures caused by fluoxetine overdose. Am J Emerg Medicine; 16:328329.

Hargrave R, Martinez D and Bernstein A (1992): Fluoxetine-induced seizures. Psychosomatics; 33:236-237.

Hulten B, Adams R, Askenasi R et al., (1992): Predicting severity of tricyclic-antidepressant overdose. J Toxicol Clin Toxicol; 30: 161170.

Isbister G, Bowe S, Dawo A et al., (2004): Relative toxicity of selective serotonin reuptake inhibitors (SSRIs) in overdose. Clin Toxicol; 42:277-285.

Isbister G, Dawson A and Whyte I (2001a): Comment: serotonin syndrome induced by fluvoxamine and mirtazapine. Ann Pharmaco ther; 35:1674-5

Isbister G, Dawson A and Whyte I (2001b): Citalopram overdose, serotonin toxicity, or neuroleptic malignant syndrome? Can J Psychiatry, 46:657-9.

Isbister G, Downes F and Whyte I (2003): Olanzapine and serotonin toxicity. Psychiatry Clin Neuro sci; $57: 244$

Kaplan L (1984): Glucose. In: Clinical Chemistry, Louis S (ed.), Mosby Co;Toronto, PP: 10321036.

Kiberd M and Minor S (2012): Lipid therapy for the treatment of a refractory amitriptyline overdose. CJEM; 14(3):193-197.

Klein-Schwartz W, Benson B, Lee S et al., (2012): Comparison of citalopram and other selective serotonin reuptake inhibitor ingestions in children. Clin Toxicol (Phila); 50(5):418-23.

Lane R and Baldwin D (1997): Selective serotonin reuptake inhibitor induced serotonin syndrome: review. J Clin Psycho pharmacol; $17: 208-21$.
McKenzie M and McFarland B (2007): Trends in antidepressant overdoses. Pharmaco epidemiol. Drug Saf; 16(5):513-523.

Mills K (2005): Cylic Antidepressants. In: Brent J, Wallace KL and Burkhart KK (eds) Critical care toxicology: diagnosis and management of the critically poisoned patient. Philadelphia, PA: Elsevier Mosby, pp.475-484.

Monte A, Chuang R and Bodmer M (2010): Dextromethorphan, chlorphenamine and serotonin toxicity: case report and systematic literature review. Br J Clin Pharmacol. Dec;70(6):794-798.

Neely J (1998): Tonic clonic seizures and tachycardia induced by fluoxetine (Prozac) overdose. W V Med J; 94(5):283-285.

Oke A, Adhiyaman V, Aziz K et al., (2001): Dosedependent seizure activity associated with fluoxetine therapy. Q J Med; 94:113-115.

Olgun H, Yildirim Z, Karacan M et al., (2009): Clinical, electrocardiographic, and laboratory findings in children with amitriptyline intoxication. Pediatr Emerg Care; 25: 170173.

Pacher P and Kecskemeti V (2004): Cardiovascular side effects of new antidepressants and antipsychotics: new drugs, old concerns? Curr Pharm Des; 10(20): 2463-2475.

Paksu S, Duran L, Altuntas M et al., (2014): Amitriptyline overdose in emergency department of university hospital: evaluation of 250 patients. Hum Exp Toxicol; 33(9):98090.

Paksu S, Zengin H, Uzun A et al., (2015): Can empirical hypertonic saline or sodium bicarbonate treatment prevent the development of cardio-toxicity during serious amitriptyline poisoning? Experimental research. Cardio vasc J Afr; 26(3):134-139.

Phillips S, Brent J, Kulig K et al., (1997): Fluoxetine versus tricyclic anti-depressants: a prospective multicenter study of antidepressant drug overdoses. The Journal of Emergency Medicine, (15): 4:434-445.

Power B, Pinder M, Hackett L et al., (1995): Fatal serotonin syndrome following a combined overdose of moclobemide, clomipramine and fluoxetine. Anaesth Intensive Care;23:499 502.

Prakash S and Rathore C (2016): Serotonin syndrome presenting as surgical emergency: A report of two cases. Indian J Crit Care Med; 20(2):120-122.

Prasher V (1993): Seizures associated with fluoxetine therapy. Seizure; 2 :315-317.

Rajamani S, Eckhardt L, Valdivia C et al., (2006): Drug-induced long QT syndrome: hERG K+ channel block and disruption of protein trafficking by fluoxetine and norfluoxetine. $\mathrm{Br}$ J Pharmacol; 149(5):481-489.

Reichert C, Reichert P, Monnet-Tschudi F et al., (2014): Seizures after single-agent overdose 
with pharmaceutical drugs: analysis of cases reported to a poison center. Clin Toxicol (Phila); 52(6):629-634.

Reith F, Van den Brande R, Synnot A et al., (2016): The reliability of the Glasgow Coma Scale: a systematic review. Intensive Care Med. 42(1):3-15.

Rothrock S, Green S, McArthur C et al., (1997): Detection of electrolyte abnormalities in children presenting to the emergency department: a multicenter, prospective analysis. Detection of Electrolyte Abnormaliti es in Children Observational National Study (DEACONS) Investigators. Acad Emerg Med; 4(11):1025-1031.

Rui T, Mary R, Gongliang Z et al., (2014): Changes in Intensity of Serotonin Syndrome Caused by Adverse Interaction between Monoamine Oxidase Inhibitors and Serotonin Reuptake Blockers. Neuro psycho pharmacology. July; 39(8): 1996-2007.

Shah N and Jain A (2016): Serotonin syndrome presenting as pulmonary edema. Indian $\mathrm{J}$ Pharmacol; 48(1):93-95.

Singhi S (2004): Hyponatremia in hospitalized critically ill children: current concepts. Indian J Pediatr; 71: 803-807.29-31.

Spindelegger C, Papageorgiou K, Grohmann R et al., (2014): Cardiovascular adverse reactions during antidepressant treatment: a drug surveillance report of German-speaking countries between 1993 and 2010. Int J Neuro psycho pharmacol; 18(4):1-9.

Suchard J (2008): Fluoxetine Overdose-Induced Seizure. West J Emerg Med; 9(3): 154-156.
Szólics M, Chaudhry M, Ljubisavljevic M et al., (2012): Neuro-imaging findings in a case of fluoxetine overdose. J Neuro radiol; 39(4):254-257.

Taylor J (1990): Statistical technique for data analysis. 2nd ed. Lewis Pub. Inc. USA. p.25-30.

Van de Loo A, Arendts W and Hohnloser S (1994): Variability of QT dispersion measurements and the surface electrocardiogram in patients with acute myocardial infarction and in normal subjects. Am J Cardiol; 74: 11131118.

Waring W, Gray J and Graham A (2008): Predictive factors for generalized seizures after deliberate citalopram overdose. Br J Clin Pharmacol; 66:6: 861-865.

Weber J (1989): Seizure activity associated with fluoxetine therapy. Clin Pharmacol; 8:296298.

Whyte I and Dawson A (2002): Redefining the serotonin syndrome. J Toxicol Clin Toxicol; 40:668-9.

Whyte I, Dawson A and Buckley N (2003): Relative toxicity of venlafaxine and selective serotonin reuptake inhibitors in overdose compared to tricyclic-antidepressants. Q J Med; 96:369374

Woolf A, Erdman A, Nelson L et al., (2007): Tricyclic antidepressant poisoning: an evidence-based consensus guideline for out-of-hospital management. Clin Toxicol (Phila); 45: 203233.

Wu M and Deng J (2011): Fatal serotonin toxicity caused by moclobemide and fluoxetine overdose. Chang Gung Med J; 34(6):644-649. 


\section{الملخص العربح)}

\section{دراسة السميه الحاده للفلوكسيتين مقارنة بالأميتريبتلين والعوامل التنبؤيه للمضاعفات}

\section{جيهان بشري عزب و اجلال حسن العوضي}

الهدف من هذه الدراسه هوفحص المرضى المتعرضين لجرعه فلوكسيتين زائده مقارنه بالاميتريتلين بالاضافه الي بحث العوامل التنبؤيه لحدوث المضاعفات. الطرق: اجريت هذه الدراسه المستقبليه الرصديه في مركز السموم -مستشفيات عين شمس الجامعيه- خلال الفتره بين يناير با.ب

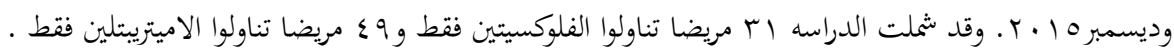

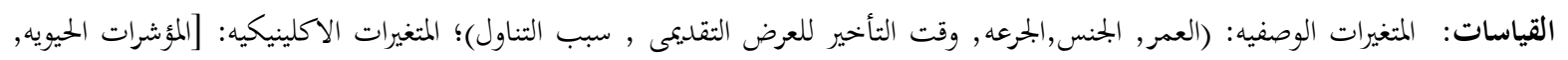

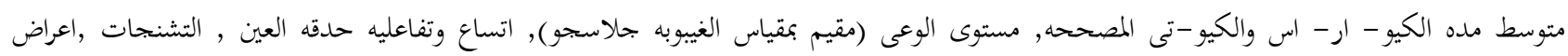

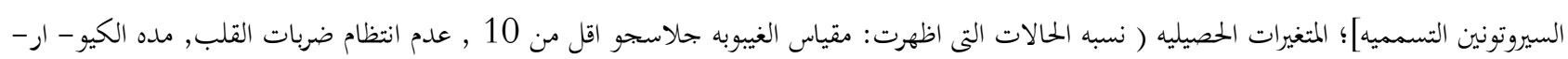

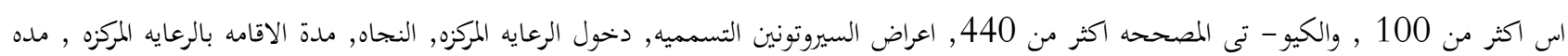

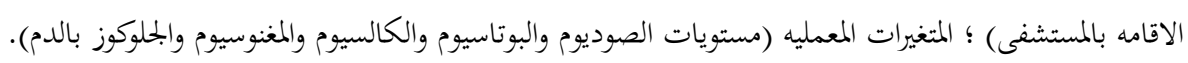

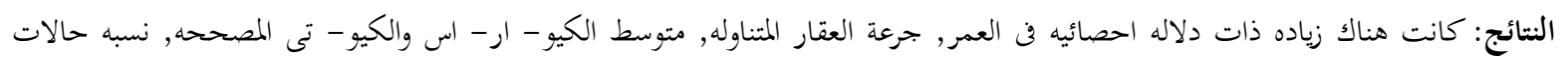

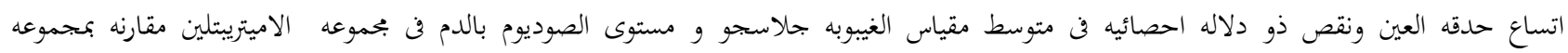

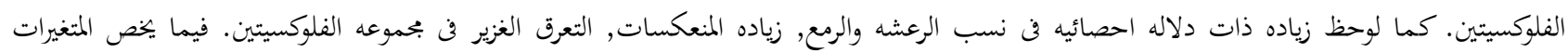

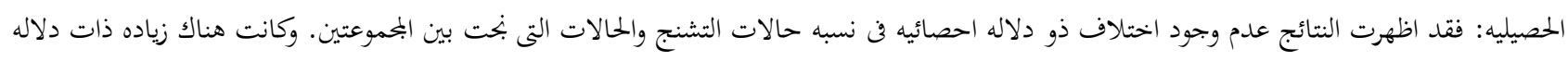

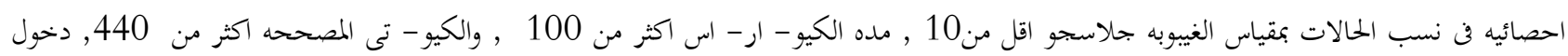

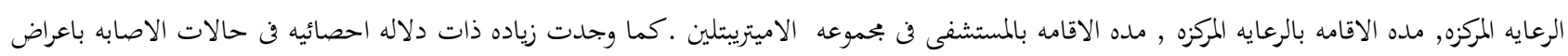

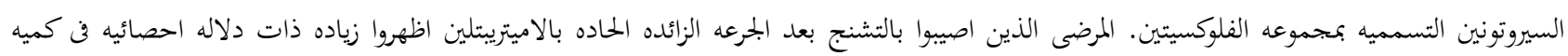

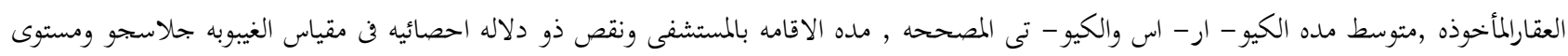

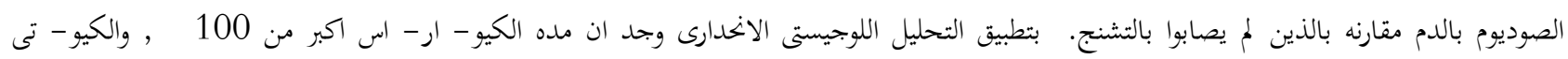

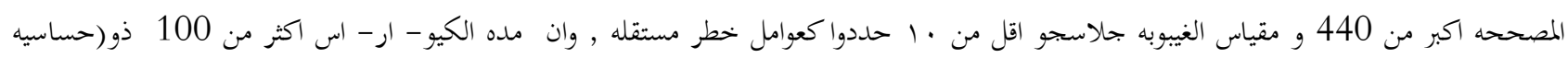

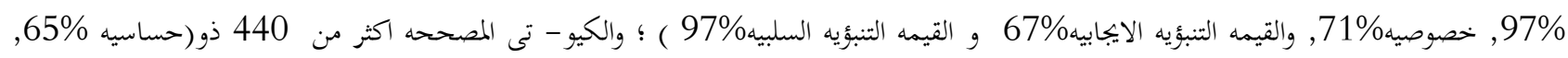

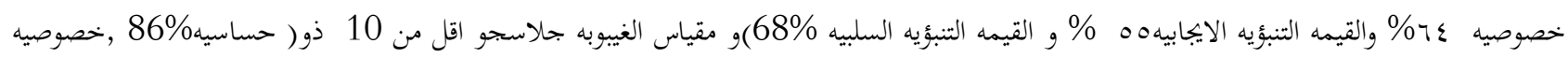

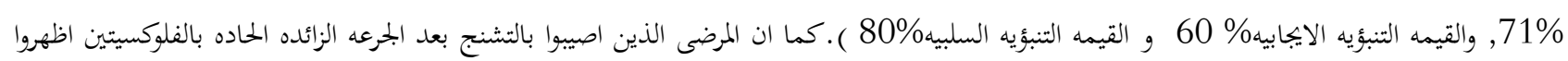

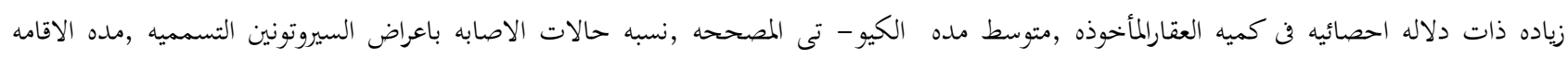

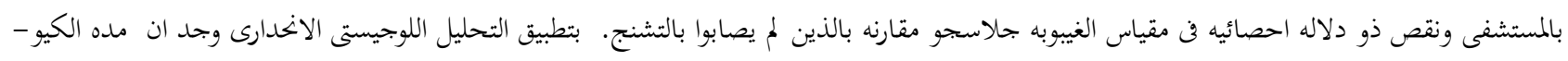

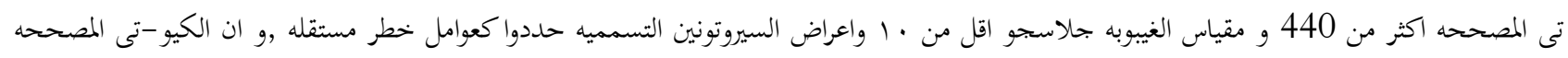

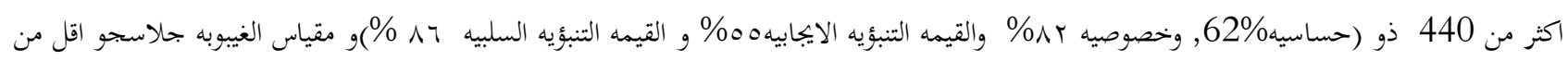

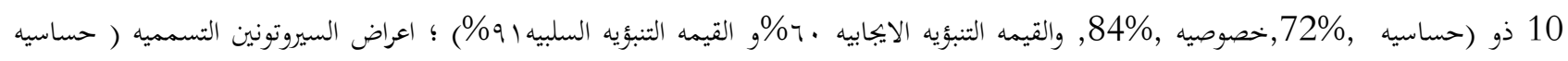

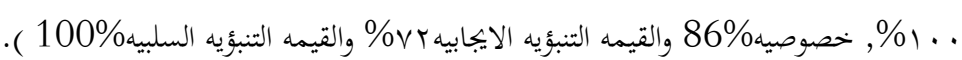

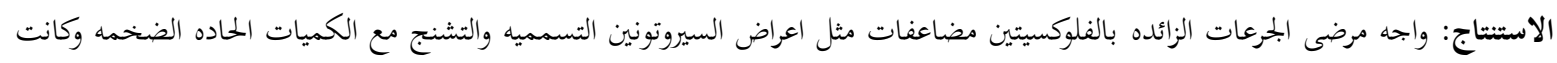

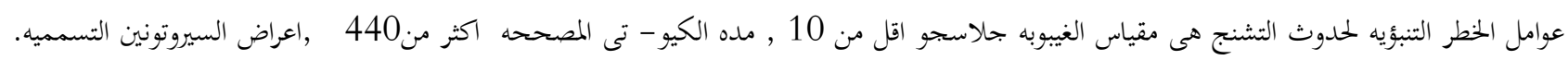

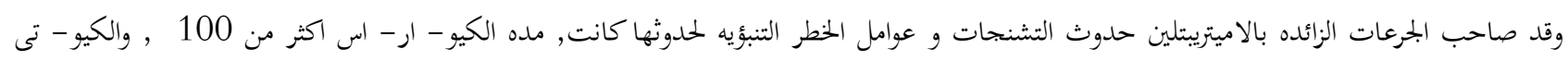

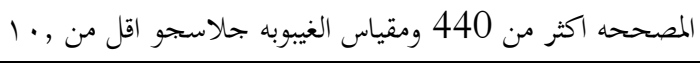

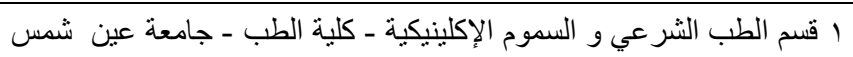

